\title{
SOBRE ALGUNAS PARTICULARIDADES DE LA CREACIÓN LÉXICA EN EL ESPAÑOL ARGENTINO ACTUAL
}

\author{
Wiaczesław Nowikow \\ Universidad de Łódź
}

\begin{abstract}
The aim of this paper is to analyze of some lexical particularities of the Argentine variant of the Spanish language. The author presents the different formal, semantic and mixed moods of lexical creation. The study explores matters related to the semantic and structural status of the lexical unit bombacha(s). The special attention is dedicated to the semantic reanalysis based on the false segmentation and reformulation of the words. Furthermore, the main emphasis is put on the reinterpretation of the lexical units minibus and especially buquebús.
\end{abstract}

En este estudio nuestras observaciones van a girar en torno a los procedimientos de creación léxica en el español argentino actual, dedicando especial atención a algunos casos del léxico patrimonial y al papel que desempeña en las creaciones en cuestión el mecanismo de reanálisis. Enfocándolo desde una perspectiva más general, nuestro objetivo será el análisis de algunas cuestiones relacionadas con la problemática del cambio lingüístico, examinada esta última sobre todo con respecto a las modificaciones léxicas, tanto formales (estructurales) como semánticas ${ }^{1}$.

Los argentinismos léxicos son muy numerosos y se dan a menudo en situaciones prototípicamente cotidianas, es decir, en las tiendas, en los restaurantes, en el transporte público, etc. Entre otros, y solo a título de ejemplo, cabe recordar, p. ej., remera (esp. pen. camiseta), mozo (esp. pen. camarero), subte (forma truncada de

\footnotetext{
${ }^{1}$ Véase, a este último respecto, p. ej. Kacprzak (2000) o Nowikow (2016).
} 
subterráneo; esp. pen. metro), malla (esp. pen. 1. correa (de reloj), 2. bañador), pileta (de natación) (esp. pen. piscina), vereda (esp. pen. acera), boletería (esp. pen. taquilla), departamento (esp. pen. piso), vidriera (esp. pen. escaparate), pollera (esp. pen. falda), etc.

Además, hay argentinismos léxicos que se manifiestan sobre todo a nivel sintagmático-discursivo-situacional. Éste es el caso de ¡hola! o ¡aló! usados para atender una llamada telefónica (esp. pen. ¡diga!, ¡dígame! o ¡sí!) o del saludo ¡buen día! empleado al lado de ¡buenos días! por la mañana (según el Diccionario del español actual [a continuación $D E A$ ], en España ¡buen día! es de uso regional). Curiosamente, el marcador discursivo ¡Listo!, quizá el más típico y frecuente para la conversación coloquial argentina, no se encuentra en diccionarios del español argentino, tales como el Diccionario del español de Argentina (a continuación $D E A R$ ) y el Diccionario del habla de los argentinos (a continuación DHA). Se trata de un elemento bastante polisémico que, según sea el caso, puede equivaler a ¡Vale!, ¡De acuerdo!, ¡Está bien! ¡Bien!, etc., dependiendo su sentido de entonación, elementos antepuestos y pospuestos, etc.

No obstante, a pesar de la abundancia de argentinismos léxicos, habitualmente tenemos que ver con una cantidad de mecanismos de creación bastante reducida. En este sentido, son emblemáticos los casos de tres argentinismos léxicos tan cotidianos como frutilla, arveja y bombacha(s).

El primero corresponde al vocablo peninsular fresa, el segundo significa guisante, mientras que el tercero se refiere a lo que en España se denomina habitualmente bragas. Como se ve, en el caso de frutilla se trata del procedimiento de derivación realizado mediante el sufijo diminutivo -illo/a. Dicho sea de paso, el sufijo en cuestión no disminuye nada, pues, como se señala en el Diccionario de la lengua española de la Real Academia Española (a continuación DRAE), frutilla es especie de fresón, es decir, fruto de una fresera oriunda de Chile, semejante a la fresa, pero de volumen mucho mayor. Cabe, además, observar que la misma derivación es posible también, en principio, en el español peninsular. Sin embargo, esta última no produce un cambio denotativo, matizando el sufijo -illo/a el significado de la palabra fruta más bien estilísticamente. En resumen, en el caso del argentinismo frutilla se da una modificación formal acompañada de un cambio de referencia y significado.

En cambio, la palabra arveja se emplea en España, pero con significado de algarroba al designar tanto la planta como la semilla de esta. En algunas variedades diatópicas peninsulares el vocablo en cuestión incluso significa lo mismo que en Argentina, es decir, guisante. Sin embargo, por ejemplo, en los supermercados argentinos y españoles se suele recurrir a los términos arveja 
y guisante, respectivamente. De modo que, a diferencia del lexema frutilla, en el caso de arveja, el cambio al afectar a la bipartición 'denotación + significado', es puramente semántico.

Es más complicada la situación con la lexía bombacha(s), en cuyo caso se trata, al parecer, de una lexía patrimonial argentina que no se encuentra en el lexicón del español peninsular estándar. En otras palabras, tenemos que ver con un criollismo o argentinismo semántico-estructural creado mediante a) modificación morfemática y b) cambio de aplicación y de significado. Etimológicamente, este argentinismo se ve relacionado con el término castellano peninsular bombacho(s) que funciona como adjetivo (véase, p. ej., DRAE: pantalón / calzón bombacho) o sustantivo (véase Diccionario práctico de la lengua española, a continuación DPLE: lleva unos bombachos horribles).

De modo que en el español actual se dan dos formas parónimas: bombacho(s) y bombacha(s). La primera, bombacho(s), es de alcance panhispánico, es decir, se da en varias comunidades hispanohablantes designando, en algunas, el pantalón que se ciñe a las rodillas o a las pantorrillas (variedad peninsular, cf. el $D R A E$ y el $D E A$ ) y en otras, a los tobillos (ciertas variedades americanas, cf. el DRAE o el Diccionario panhispánico de dudas de la Real Academia Española y de la Asociación de Academias de la Lengua Española, a continuación $D P D$ ). En cambio, el vocablo bombacha(s) es un americanismo de carácter regional (es frecuente en el Cono Sur) con sentido de pantalón con perneras anchas que se ajustan en los tobillos, lo que quiere decir que, en este caso, puede ser sinónimo del panhispánico bombacho(s). Recordemos con este motivo que el vocablo bombacha(s) no se encuentra, p. ej., en el $D E A$ y que en el $D R A E$ esta voz aparece solo como un americanismo ${ }^{2}$. Por su parte, en Argentina y Uruguay el lexema bombacha(s) extiende su alcance semántico-referencial, adquiriendo la acepción del vocablo peninsular braga(s).

En resumen, al cambio morfemático $o \rightarrow a$ (según el $D P D$, en la zona del Caribe es posible también la variante alomórfica bombache) le corresponden los cambios de categoría gramatical (género masculino $\rightarrow$ género femenino) y de significado.

${ }^{2}$ La voz bombacho (y por lo tanto, bombacha) fue derivada, al parecer, del étimo bomba por similitud de forma, es decir, por la similitud esférica de las bombas (véase, a este respecto, Corominas (1983) que en la entrada BOMBA aporta los siguientes datos: "Por la forma esférica de las bombas: Bombacho, 1884, bombacha, arg. " pantalón ancho »”; cf. también Nowikow, 2009a: 221 y 2009b: 269-270). De hecho, en el español argentino se dan vocablos derivados tanto de la bomba 1 (máquina para elevar agua) como de la bomba 2 (proyectil). Así, a la primera se remonta la consabida bombilla, es decir, tubo para sorber el mate. En cambio, de la bomba 2 se deriva la voz argentina bombita que equivale a la peninsular bombilla (ampolla de cristal que se ilumina al pasar la corriente eléctrica) (véase Nowikow, 2009b: 269-270). 
En el castellano peninsular los lexemas determinantes de la voz bombacho(s) son pantorrilla o rodilla, mientras que en el caso del vocablo bombacha(s) este papel lo desempeña, habitualmente, la lexía tobillo.

Además, con respecto a la repartición geográfica y a los cambios de aplicación y de significado, en el caso de la palabra bombacha(s) podemos distinguir tres dimensiones semántico-referenciales (cf. Nowikow, 2010: 427):

1) en varias regiones hispanoamericanas bombacha(s) significa 'calzón, pantalón bombacho', es decir, con perneras anchas, sin que se precisen los países ni la manera de ajustar el pantalón (cf. $D R A E)$;

2) como se señala en el $D P D$, en los países del Cono Sur es 'pantalón ancho que se ajusta en los tobillos'; según el mismo diccionario, en otras zonas del ámbito hispánico se emplean las variantes masculinas bombacho y bombache; no obstante, dichas regiones no se precisan y solo se menciona que bombache(s) se usa en zonas del Caribe (véase supra);

3) según varias fuentes lexicográficas (el $D R A E$, el $D E A R$ y el $D H A$ ), en Argentina y Uruguay bombacha(s) posee dos acepciones específicas: a) 'pantalón del gaucho' (se extiende, en general, a 'hombres de campo') y b) 'prenda interior femenina desde la cintura hasta el comienzo de los muslos' (esp. pen. bragas).

Recapitulando, la creación argentina bombacha(s) es un neologismo formal que al mismo tiempo se caracteriza por los cambios de aplicación y de significado. Se trata pues de una innovación semántico-formal respecto al lexicón castellano peninsular que, como se ha señalado supra, carece de dicho vocablo.

Pasemos ahora a un caso más complicado, es decir, a la creación neológica relacionada con el fenómeno de reanálisis. Como es sabido, el reanálisis (o la reinterpretación) ha sido objeto de interés de varios autores ${ }^{3}$. Las causas del reanálisis radican, a menudo, en la inadecuada interpretación por parte de los hablantes de la forma y del contenido de las unidades significativas, así como de las relaciones establecidas por estas últimas con otros elementos lingüísticos. La reinterpretación se da tanto en el caso de las unidades gramaticales como en el de las léxicas. Además, unas pueden ser reanalizadas en términos de otras, es decir, un elemento léxico se gramaticaliza o al revés, un elemento gramatical se lexicaliza. Así, según Ridruejo (1989: 74), el sustantivo mente quedó gramaticalizado en las lenguas romances como sufijo formador de adverbios de modo: claramente, precipitadamente, etc. En cambio, la secuencia bus, procedente del gramema latino -̌̌bŭs, quedó lexicalizada al adquirir el significado de 'vehículo automóvil de

\footnotetext{
${ }^{3}$ Véase, p. ej., Anderson (1977); Ridruejo (1989); Martín Vegas (2005); Nowikow (1995, 2009a,
} 2016). 
transporte público' (p. ej., bus en inglés o, como forma coloquial, en español o, p. ej., en polaco $)^{4}$. A consecuencia del reanálisis llevado a cabo por los usuarios, algunos lexemas (palabras) o gramemas (formas gramaticales) quedan desvinculados de sus paradigmas y categorías y se revinculan a otros paradigmas y categorías. En el caso del léxico, la reinterpretación consiste, a menudo, también en la resegmentación, operación que afecta, habitualmente, a los límites entre las unidades al dividir los hablantes las palabras tanto de acuerdo con la estructura morfológica como sin respetar esta última. De modo que los formantes y los vocablos creados a través del reanálisis, con frecuencia, son erróneos e incorrectos desde el punto de vista morfológico. Todo esto conduce a las reformulaciones de dos o más elementos en términos de uno solo o, al revés, a la distinción de dos o más segmentos allí donde existe solo uno. De hecho, el proceso de reinterpretación consiste en dos etapas: en la de segmentación impropia y en la de reformulación de los segmentos. En cambio, desde el punto de vista de la composición de palabras, se distinguen la división en segmentos de identidad y la posible fusión de los elementos segmentados con otros segmentos.

Por ejemplo, la vozinglesa orange proviene de la española naranja. No obstante, al pasar por la primera etapa norange: esp. naranja $>$ ingl. norange y al juntarse la palabra en cuestión con el artículo indefinido $a(n)$, los usuarios reanalizaron erróneamente la secuencia a norange considerando la $/ \mathrm{n} /$ inicial como parte del artículo an que en inglés se emplea con los sustantivos que empiezan por vocal ${ }^{5}$. De ahí que norange pasara a orange siendo la primera etapa naranja $>$ norange y la segunda, a norange $>$ an orange. De modo que el reanálisis consistente en una segmentación y en una fusión erróneas, pero justificadas desde el punto de vista morfológico, determinó la creación de un neologismo léxico.

Una reinterpretación semejante tuvo lugar en el caso de las palabras creadas a partir del modelo de la voz hamburger que al resegmentarse erróneamente en ham + burger, creó en diferentes lenguas un nuevo paradigma léxico con significado de "bocadillo con X". Recordemos que en alemán hamburger es un adjetivo que significa 'de la ciudad de Hamburgo o perteneciente a la ciudad de Hamburgo' (cf. derivaciones adjetivales tales como berliner, frankfurter, etc.). Esto quiere decir que la resegmentación basada en ham (esp. 'jamón') es falsa. En cambio, el reanálisis del formante burger provocó que este último se lexicalizara y se convirtiese en el portador del significado de "bocadillo". De ahí, por analogía fueron creadas voces tales como cheeseburger, chiliburger, tomatoburger,

${ }^{4}$ Como señalaba Moreno de Alba (2003: 436), los mexicanos que viven en México en ciudades fronterizas norteñas y trabajan al otro lado de la frontera, utilizan a menudo anglicismos tales como bos ('bus'), troca ('truck'), marqueta ('market'), guachar ('to watch'), etc.

${ }^{5}$ Pinker (1995: 267), apud Martín Vegas (2005: 271-272); véase también Nowikow (2016: 116). 
beefburger, baconburger, etc ${ }^{6}$. Complementando estas observaciones, podemos señalar que registramos el neologismo siloeburger en un café polaco llamado "Siloe" (Siloé bíblico). Por otro lado, como señalaba Moreno de Alba (2003: 449), la palabra burger es un extranjerismo que se emplea cada vez más en México.

No obstante, lo que nos interesa más en este caso son las consecuencias del reanálisis para la creación del léxico argentino. Hay un caso interesante e importante, porque representa el mecanismo de reanálisis en plena evolución. Se trata del campo semántico de los medios de transporte y, en concreto, de las lexías que designan los vehículos conocidos en España como autobús o autocar. Nos referimos a vocablos tales como ómnibus, colectivo y micro. La reinterpretación del término ómnibus condicionó la creación de varias palabras con el formante -bus en diferentes lenguas. Como es sabido, en sus orígenes, omnibŭs era la forma

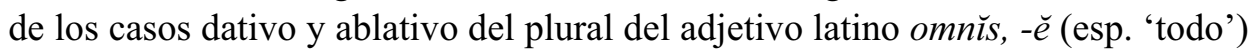
que pertenecía a la tercera conjugación y significaba, etimológicamente, "para todos". En el siglo XIX, al designar la nueva realidad extralingüística, omnı̌bŭs adquirió el significado de "vehículo de transporte colectivo para trasladar personas, generalmente dentro de las poblaciones. Tren ómnibus: El que lleva vagones de todas clases y para en todas las estaciones" (DRAE).

Más tarde la voz en cuestión fue sometida a la resegmentación errónea omni - bus. Recordemos que en latín -ǐbŭs era la marca gramatical del dativo. No obstante, como es bien sabido, los casos habían desaparecido en la época de transición del latín hispánico al romance. De modo que los hablantes identificaron omni como portador del significado léxico "todo", mientras que bus quedó reinterpretado como lexema con significado de "medio de transporte colectivo para varias personas". Actualmente, la palabra bus se emplea con este significado en inglés y, siendo préstamo de esta lengua, en otros idiomas? ${ }^{7}$.

Hoy en día, como señala el DRAE, la palabra ómnibus se emplea con el significado de "autobús" en Argentina, Bolivia, Ecuador, Paraguay y Perú. En cambio, el $D P D$ matiza que se trata de "vehículo de transporte colectivo por carretera" al advertir que en España dicha voz significa "tren que para en todas las estaciones". Por su parte, el DEA define ómnibus como "vehículo de motor, para

\footnotetext{
${ }^{6}$ Anderson (1977: 259); Bynon (1981: 66); Nowikow (2009a: 223 y 2016: 116).

${ }^{7}$ Según Webster's Students Dictionary (WSD), bus proviene de la segmentación de la palabra francesa omni-bus. La resegmentación omni-bus se actualizó en varias lenguas a través de creaciones tales como esp. autobús, microbús, fr. airbus (la marca del famoso avión), ing. waterbus. Cabe subrayar que la actualización tiene carácter internacional. Por ejemplo, el término autobús se emplea en muchísimas lenguas, mientras que microbús se utiliza con significado de "autobús de menor tamaño que el usual" (DRAE) en lenguas indoeuropeas pertenecientes a grupos diferentes tales como, por ejemplo, el español peninsular y el polaco.
} 
el transporte público urbano o interurbano, con capacidad para varias decenas de personas" señalando que en España las equivalencias de este son autobús y autocar. Al mismo tiempo en el $D E A$ se menciona que en el español argentino, como sinónimo de ómnibus, se emplea el término colectivo, siendo las definiciones de ambos términos idénticas.

En el español de Argentina actual hemos documentado dos casos que parecen seguir el modelo de reanálisis comentado supra. Nos referimos a las lexías minibús y buquebús. La primera palabra designa autobuses más pequeños que circulan, por ejemplo, en Buenos Aires y que suelen llevar en torno a 20 pasajeros. Hay una coincidencia curiosa: en Polonia funciona exactamente el mismo término minibus usado con referencia a un objeto con características muy parecidas.

En cambio, el caso de buquebús parece ser más complicado y problemático. En primer lugar, cabe señalar que se trata de una composición de dos sustantivos que mantienen, en gran medida, su autonomía con respecto a la designación y al significado final unitario. Admitimos en este caso la posible autonomía de bus como sustantivo con significado de "medio de transporte colectivo para varias personas" (véase infra). El término buquebús funcionó al principio como nombre de la compañía "BUQUEBUS" que prestaba servicios de transporte por vías marítima y terrestre entre Buenos Aires y ciudades uruguayas Montevideo y Colonia. Como se señala en un folleto de información, el servicio "incluye pasajes de ida y vuelta Buenos Aires - Colonia en el buque Eladia Isabel (3 horas de viaje) con combinación de bus a Punta del Este". Es significativo el empleo autónomo de bus, vocablo que hemos documentado también en otros contextos: bus Colonia - Montevideo, bus desde Punta del Este, fecha y hora del bus.

Hoy en día el término buquebuis, siendo en sus orígenes nombre de una compañía marítima, de una manera metonímica, se emplea en el español argentino coloquial como denominación del medio de transporte que realiza viajes entre Buenos Aires y localidades uruguayas. Así, al lado de He viajado con el buquebús (= BUQUEBUS), se escucha en boca de algunos hablantes porteños también $\mathrm{He}$ viajado en buquebús. Al parecer, se trata de una lexicalización en curso todavía no muy estable. Sin embargo, es probable que la lexicalización completa no tarde mucho, lo que, hasta cierto punto, se ve comprobado por el hecho de que al preguntar a algunos hablantes porteños, qué era para ellos buquebús, estos contestaban: "El buque que realiza viajes entre Buenos Aires y Montevideo o Colonia". Cabe subrayar que mis interlocutores se referían a viajes directos, es decir, sin combinación de bus entre, por ejemplo, Colonia y Montevideo.

Al concluir, señalemos que el español argentino actual ofrece varias posibilidades de creación léxica. En algunos casos, prevalece el factor formal siendo el cambio semántico consecuencia de este último (p. ej., el lexema frutilla). 
Por otro lado, hay cambios sin modificaciones estructurales que afectan al referente y al significado (cf. la lexía arveja). En tales situaciones en el cambio predomina el factor semántico. Subrayemos que en ambos casos se trata de palabras que, aunque con diferentes características diafásicas y diatópicas, existen en el español peninsular.

Además, el español argentino cuenta con neologismos semánticoestructurales que al proceder de los étimos castellanos, no existen, sin embargo, en el español peninsular. De modo que se trata de los criollismos tanto formales como semánticos. Este es el caso de la lexía bombacha(s) cuyas estabilidad y difusión léxicas se ven confirmadas por la productividad derivativa y por la capacidad de formar parte de unidades fraseológicas. Se trata, p. ej., de vocablos bombachón o bombachudo, ambos con significado de "pantalón fruncido que usan las mujeres para hacer gimnasia, que cubre hasta la mitad del muslo y se ciñe a este mediante un elástico" (esp. pen. pololos; cf. el DEA). Además, el vocablo bombachón significa también "pantalón corto y amplio para bebés que se ciñe en la cintura y en los muslos mediante un elástico" (véase el $D E A$ ). Por otro lado, la lexía bombacha(s) forma parte de secuencias tales como bombacha biquini ("bombacha de tamaño reducido", esp. pen. braguita bikini; cf. el DEA), bombacha o bombachita de goma ("prenda de vestir del bebé, confeccionada en un material elástico e impermeable"; cf. el $D E A$ ) o de la unidad fraseológica perder las bombachas (por alguien): \{una mujer pierde las bombachas por un hombre\}, es decir, "sentir una mujer amor ciego por un hombre", lo que equivale, tanto en España como en Argentina, a estar loca por o, en el caso de este último país, a perder los calzones (véase el $D E A$ ).

$\mathrm{Y}$ finalmente, last but not least, el español argentino recurre en el proceso de la creación léxica al mecanismo de reanálisis, siguiendo los modelos ya existentes y actualizando las respectivas resegmentaciones y reformulaciones mediante la creación de nuevos términos. Algunos de estos últimos alcanzan un alto grado de lexicalización y estabilidad (p. ej., el minibús), mientras que otros se encuentran en vías del proceso de lexicalización (p. ej., el buquebús).

\section{Referencias bibliográficas}

\section{Obras y artículos}

ANDERSON, James (1977), Aspectos estructurales del cambio lingüístico, Madrid, Gredos. BYNON, Theodora (1981), Lingüistica histórica, Madrid, Gredos.

COROMINAS, Joan (1983), Breve diccionario etimológico de la lengua castellana, Madrid, Gredos. 
KACPRZAK, Alicja (2000), Terminologie médicale française et polonaise. Analyse formelle et sémantique, Łódź, Wydawnictwo Uniwersytetu Łódzkiego.

MARTÍN VEGAS, Rosa A. (2005), « ¿Segmentación morfemática o reanálisis? Formaciones con el sufijo -idad, o *-abilidad, *-icidad, *-eidad», Moenia. Revista Lucense de Lingüística \& Literatura, vol. 11, pp. 269-281.

MORENO DE ALBA, José (2003), La lengua española en México, México, Fondo de Cultura Económica.

NOWIKOW, Wiaczesław (1995), « La causación múltiple y la poliinterpretación del cambio lingüístico », Estudios Hispánicos, n ${ }^{\circ}$ IV (« Lingüística Española: aspectos sincrónico y diacrónico ») (W. Nowikow éd.), pp. 29-39.

NOWIKOW, Wiaczesław (2009a), «Algunas observaciones sobre los mecanismos de la creación léxica en el español argentino actual », in Léxico español actual II (L. Luque Toro éd.), Università Ca' Foscari, Venezia, Libreria Editrice Cafoscarina srl, pp. 219-227.

NOWIKOW, Wiaczesław (2009b), « En torno a una creación neológica argentina: el caso de bombacha(s) ", in Panorama des études en linguistique diachronique et synchronique. Mélanges offerts à Józef Sypnicki (G. Vetulani éd.), Łask, Oficyna Wydawnicza LEKSEM, pp. 265-270.

NOWIKOW, Wiaczesław (2010), « De modificación morfemática a cambios de aplicación y de significado: sobre un neologismo parónimo en el español de Argentina », in Vues et contrevues (G. Le Tallec-Lloret éd.), Limoges, Lambert-Lucas, pp. 425-429.

NOWIKOW, Wiaczesław (2016), «El cambio lingüístico y el mecanismo de reanálisis », in Relecturas y nuevos horizontes en los estudios hispánicos. Vol. 4 (J. Wilk-Racięska, A. Szyndler, C. Tatoj éds), Katowice, Wydawnictwo Uniwersytetu Śląskiego, pp. 111-120.

PINKER, Steven (1995), El instinto del lenguaje, Madrid, Alianza.

RIDRUEJO, Emilio (1989), Las estructuras gramaticales desde el punto de vista histórico, Madrid, Síntesis.

\section{Diccionarios}

DEA: Diccionario del español actual (1999), vol. 1, M. Seco, O. Andrés, G. Ramos, Madrid, Aguilar. DEAR: Diccionario del español de Argentina (español de Argentina - español de España) (2000),

G. Haensch, R. Werner (éds), C. Chuchuy (dir.), Madrid, Gredos.

DHA: Diccionario del habla de los argentinos (2005), Academia Argentina de Letras, $3^{\mathrm{a}}$ ed., Buenos Aires, Espasa.

DPD: Diccionario panhispánico de dudas (2005), Real Academia Española, Asociación de Academias de la Lengua Española, Bogotá, Santillana.

DPLE: Diccionario práctico de la Lengua Española (1998), Madrid, Espasa.

DRAE: Diccionario de la lengua española (2001), 22 $2^{\mathrm{a}}$ ed. (versión electrónica), Real Academia Española, Madrid, Espasa Calpe.

WSD: Webster's Student Dictionary (1962), New York, American Book Company. 